\title{
Peertechz
}

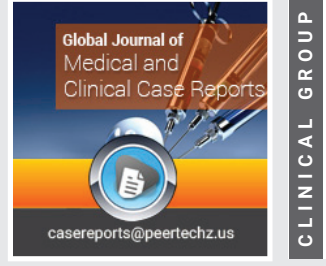

Literature Review

\section{Efficacy of cognitive}

\section{restructuring technique on}

\section{adjustment of social isolates in}

\section{a sample of nigerian secondary}

\section{school adolescences}

\author{
Damian Chijioke Ncheke ${ }^{1}$, Nneka Nwosu ${ }^{1 *}$, Nkechi Theresa \\ Egenti ${ }^{1}$, Esther E Enajedu' ${ }^{2}$, Moses Onyemaechi Ede ${ }^{1}$, Sunday \\ S Umah ${ }^{3}$, GN Omeje ${ }^{1}$ and FA Ugwu ${ }^{1}$ \\ ${ }^{1}$ Department of Educational Foundations, University in Nsukka, Nigeria \\ ${ }^{2}$ School of Foundations and General Studies, Delta State School of Marine Technology, Burutu, Nigeria \\ ${ }^{3}$ Department of Educational, Psychology, Peace Land College of Education Enugu, Nigeria
}

Received: 12 January, 2021

Accepted: 26 February, 2021

Published: 27 February, 2021

*Corresponding author: Dr. Nneka Nwosu, Department of Educational Foundations, University in Nsukka, Nigeria, E-mail:nneka.nwosu@unn.edu.ng

Keywords: Cognitive restructuring technique; Adjustment of social isolates college adolescents https://www.peertechz.com

Check for updates

\begin{abstract}
Objective: Of the study is to investigate the efficacy of Cognitive Restructuring Technique on Adjustment of Social Isolates in a sample of Nigeria Secondary School Adolescents.

Methods: Pre-test post-test randomized control trial experimental design was adopted by the researchers for the study (60). Secondary school adolescents who were drawn through proportionate stratified randomly sampling technique constituted the sample for the study. The secondary school adolescents were randomly assigned to experimental (32) and (28) groups. Social Isolates Assessment scale for Adolescents (SIASA) and Adjustment Scale of Social Isolates (ASSI) were used for data collection. SIASA and ASSI were properly validated by experts in the test development and the internal consistency reliability indices of the items estimated as 0.82 and 0.86 respectively using Cronbach Alpha method. Before the commencement of the testing and treatment package, the researchers assured the participants of confidentiality of interactions and personal information as they work together in self-disclosure. Thereafter, pre-treatment assessment (pre-test) was conducted using the SIASA and ASSI in order to collect baseline data (Time 1). After that, the experimental group was exposed to 90 minutes of the Cognitive Restructuring Technique (CRT) program twice a week for a period of 6-weeks. The treatment took place between September and November 2019. Post-test (Time 2) assessment was conducted 1 week after the last treatment session. Besides, a follow-up assessment was conducted after two months of the treatment (Time 3 ). Data collected were analyzed using repeated measures analysis of variance.
\end{abstract}

Results: The findings of the study revealed that the efficacy of cognitive restructuring technique on the adjustment of social isolates adolescents was significant at post-test and follow-up measures. One of the contributions of the findings is that if secondary school adolescents are not properly counseled, their social isolate behavior will continue to increase.

Conclusion: The contribution among others is that Federal Government or relevant education authorities should provide enough guidance counselors in the various institutions of learning who will assist in the counseling of adolescents in the dangers of social isolate behaviour using CRT. 


\section{Introduction}

Adolescents are commonly regarded as youths of today and very vital to the socioeconomic and political development of any nation. The World Health Organization (WHO) [1] defines an adolescents as any person between the ages of 10 and 19 years. This range also falls within the World Health Organization's definition of young people which refers to individuals between 10-24 years. This presupposes that being an adolescent is a transitory stage in life. For this study, adolescents are persons within the age range of 10 and 19 years currently in secondary school otherwise known as schooling adolescents. These group of people are exposed to many maladaptive behaviours such as social isolation.

Social isolate behavior is a developmental disorder usually identified by a number of negative consequences including heightened anxiety, panic attacks, eating disorders, addictions, substance abuse and violent behavior [2]. There are certain goals that require efforts of adolescents to be achieved. Human beings as a social animals need social and psychological support from their fellows in certain conditions to achieve a goal. Man as a social animal, usually maximizes his potentials and reaches his full capacity in development only in the context of association with others [3]. Social isolation, on the contrary, tends to restrain human development and usually leads to physical, mental and emotional disorder [4]. Social isolates is the act of withdrawing from society in general [5]. In such developmental disorder, there is usually not much interaction with other people. An isolate according to Ncheke [2] is that individual who is psychologically distinct from other members of the class or group. Such person who is isolated may have inferiority complex and because of that people usually disregard the individual and it has serious implication to the affected individual [4].

Isolate behavior is a developmental disorder that has a number of implications for entire society. Isolate behavior is a form of social problem where an individual continually distant himself from a given social group of which he or she ordinarily belongs [6]. Such a group can be institution, peer or academic. In the context of this study, a social isolate is that adolescent who distances himself from society as a result of psychological problem such as inferiority complex, anxiety, panic attacks among others.

The isolation of a child by his peers during secondary school years may influence the child's participation in school activities and this in turn may influence his overall performance in school and his performance later in life. In addition many children who are isolated by their peers at this early stage in life many become frustrated, develop inferiority complex and consequently lose self-confidence [2]. This of course, could cost untold destruction in the academic life of the child and by implication the educational development of the nation.

It is possible that such maladaptive behaviours like inferiority complex, frustration; loss if self-confidence among others can be positively modified and/or adjusted through a number of ways. These ways may include, individual counseling, role playing, cognitive restructuring technique among others [7]. However, while there are reports of efficacies of individual counseling, role playing and cognitive restructuring technique in other inadaptive areas like shyness, stage fright, little or no information appears to be available in the area of social isolation. Social isolation is a nagging problem that impairs with students social skill as a result of inability to adjust properly and hence must be reduced. Using the efficacy of cognitive restructuring in solving other maladaptive behaviours, would such counseling approach be effective in adjustment of social isolates among adolescents.

Adjustment is an inevitable process in the life of every individual. Adjustment refers to various activities of an individual which involves efforts to cope with his life, vocational, social and economic contingencies [8]. It implies the application of essential skills to triumph over life contingencies. The authors also noted that adjustment is the ability of individual to harmonize his mental and behavioural pattern in order to achieve his personal needs, the demands of the other individuals and that of the society. In this study, adjustment refers to the process in which an adolescents strives to satisfy his/her personal needs as well as deals with the demands, and constraints that are placed on him/her by the school environment. Such demands includes: Obeying rules and regulations, punctuality, participating in all school activities both curricular and extra-curricular activities. To acquire these skills of adjustment, counseling of students becomes important and needs urgent attention since adjustment is solution to life problem.

It seems that many secondary school adolescents are maladjusted and as such; they display such undesirable characteristics as showing off, attention seeking, nervousness, emotional instability and restlessness. The isolation of a students by his mates during school years could affect negatively the student's participation in school activities and this could affect his overall performance in school and his later life performance. There are research evidence suggesting that a high proportion of Nigerian secondary school adolescents are isolated regardless of the problem associate with it [9]. Adali (2018) noted that students who are isolated at early stage of their secondary education usually become frustrated, develop inferiority complex and lose self-confidence.

It is based on the observed gap that the researchers conducted a randomized control trial of efficacy of cognitive restructuring counseling technique on the adjustment of social isolates in a sample of Nigerian secondary school adolescents. In this study, it was hypothesized that cognitive restructuring technique has significant effect in adjusting social isolate secondary school adolescents in Enugu state Nigeria at three points of assessment.

\section{Literature review}

Literature showed that over 40 percent of Nigerian secondary school adolescents perform poorly and are maladjusted due to social isolation [10]. Leo [11] has argued that there is an urgent need for the Federal Government of Nigeria to address the

Citation: Ncheke DC, Nwosu N, Egenti NT, Enajedu EE, Ede MO, et al. (2021) Efficacy of cognitive restructuring technique on adjustment of social isolates in a sample 
issue of secondary school adolescents that are socially isolated. Research indicates that the major cause of students difficulties in social learning is lack of social acceptance [12]. Finberget (2002) and Goertzan [13]. A study conducted by Finberget (2002) found that children of low social acceptance tend to lack desirable and positive personality traits whereas children with high social acceptance among peers tend to exhibit desirable and positive personality traits. Moreso, children who are not socially accepted by their peers tend to display such undesirable traits as showing off, nervousness, and emotional instability Calif [14], Lunni [15,16]. This implies that students with such traits lack self control. Children who are not socially accepted by their peers also show inferiority complex, anxiety and panic attacks [4]. It is possible that the undesirable traits of the non-socially accepted are the cause of lack of social acceptance. It is also likely that a lack of social acceptance helps to produce much of the unacceptance behaviours of secondary school students [2]. This study suggests that one important function of the mental health counselor is to break into the vicious circle where lack of acceptance by peers helps to produce unacceptable behaviour and unacceptable behavior tends to generate lack of peer acceptance.

However, maladaptive or rather inappropriate behavior can be reduced or adjusted through behavior modification techniques. Different kinds of behavior modification techniques such as rational emotive behavioural therapy, psychodrama, role therapy, psychodrama, role therapy, avertive therapy, reinforcement among others have been used for intervention on maladaptive behavior among school children [4,17-19].

Adumah [20] have also suggested that psychological principles and the experiences of mental health counselor and those therapists who have worked with isolates persons support the following techniques for helping rejected and isolated students achieve a place in the class group. These techniques include finding special skills, training in skills (already acquired), discussion, using peer helpers and group guidance [4]. However, all the techniques are used in counseling approach like Cognitive Restructuring Technique (CRT) hence, the researchers sought to investigate the efficacy of CRT on adjustment of social isolates in a sample of secondary school adolescents. This, may be could be necessary because the area of social islates adjustment appears somehow neglected.

Cognitive Restructuring Technique (CRT) in counseling is very effective in handling a lot of maladaptive behaviours. Cognitive restructuring involves the process of reframing negative and unrealistic thoughts to realistic and positive thinking [21]. Social isolates of secondary school adolescent is a negative and unrealistic behavior. This implies that if adolescents receive cognitive restructuring programme that they will refrain from negative thoughts that is social isolation and think positively. Living Stone (2008) posit that Cognitive Restructuring is a technique for altering negative or self-defeating thought patterns deliberately replacing them with positive constructive self-talk. In this study, Cognitive Restructuring refers to a conselling technique used in helping secondary school adolescents to change their irrational and unprofitable thought patterns to positive and useful ways of thinking that will be more rewarding in life. Cognitive Restructuring as a technique in counseling is effective in reducing a lot of maladaptive behaviours. For instance [22], found out in his study that Cognitive Restructuring was effective in reducing examination phobia among students. Also Mejo [23] noted that CRT had positive effect on the tendencies to engage in examination malpractice. However, Enofa [24] found out that students who were exposed to CRT adjusted on their anger behavior more than those who were not exposed to treatment. Because social isolation is a developmental disorder or rather connected to maladaptive behaviours such as lack of self control, nervousness, emotional instability, low self-esteem among others, the use of cognitive restructuring technique has been suggested as a remedy [4,22,23,25]. Undaah (2015) posits that in CRT, isolates are taught to refrain from negative thoughts and develop a mindset that enables than to persist better in doing aversive tasks. Thus, this study assessed the efficacy of CRT based program in the adjustment of secondary school adolescents social isolate behaviours.

\section{Method}

\section{Design of the study and participants}

The pre-test, post randomized control trial experimental design was adopted. Subjects were randomized into experimental and control groups. A total of 60 secondary school adolescents comprising male $(n=32)$ and female $(n=28)$ from sampled public secondary schools in Enugu state Nigeria who met the inclusion criterion constituted participants for the study. G-power, version 3.1 gave 0.92 which is an adequate sample size for this study (Paul, et al., 2007). Sixty (60) identified isolate adolescents from mental health counsellor's log book who were drawn through proportionate stratified random sampling technique constituted the sample for the study. These adolescents were stratified based on the high number of identified isolates in co-educational secondary schools (Model Secondary School, Urban Secondary School and Community Secondary School Alor Uno). From where the adolescents were proportionately sampled (16 Model Secondary School, 29 Uban Secondary School and 15 Community Secondary School Alor Uno). A total of 269 adolescents showed interest and volunteered to participate in the intervention program. All the 269 adolescents volunteers participate in the study were screened for eligibility based on the eligibility criteria set by the researchers including that: (1) the identified isolate adolescents must be secondary school students in public schools; (2) adolescents must have an element of social isolate behavior. Volunteers who did not meet all the inclusion criteria were excluded. After that, the 60 secondary school adolescents who met all the inclusion criteria were randomly assigned to experimental and control groups' conditions using a simple randomization procedure (participants were asked to pick 1 envelope containing pressure-sensitive paper labeled with either E-experimental group or C-control group from a container. The adolescents were randomly assigned to experimental (32) and control (28) groups as shown in Figure 1.

Citation: Ncheke DC, Nwosu N, Egenti NT, Enajedu EE, Ede MO, et al. (2021) Efficacy of cognitive restructuring technique on adjustment of social isolates in a sample 


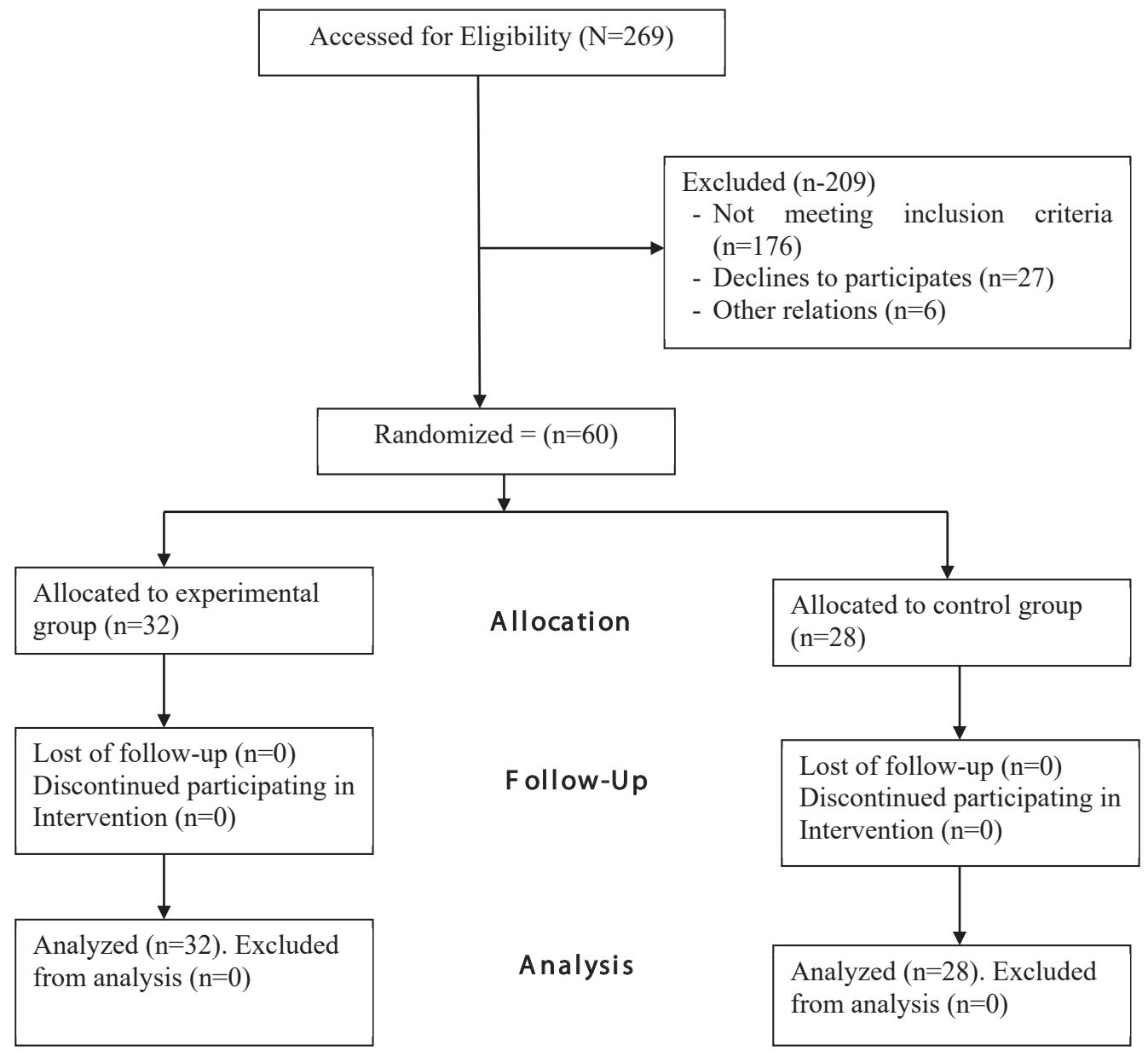

Figure 1: Sampling Distribution for the Study.

\section{Measures}

Demographic questionnaire: A demographic questionnaire was administered to the adolescents (participants) in order to obtain their demographic characteristics such as gender, age, and location. Each of the participants was instructed to tick the appropriate demographic information that may be applicable to him or her Table 1.

\section{Social Isolate Assessment Scale for Adolescents (SIA- SA)}

Social Isolate Assessment Scale for Adolescents (SIASA) developed by the researchers was used for data collection. SIASA is a 24-items scale with five response options of Not At All (1), Almost Never (2), Sometimes (3), Nearly Always (4), Always (5) which was properly validated by three experts in the area of test development. Example of item statement on SIASA is "I read in group with my classmates". A minimum of 20 points and a maximum of 100 points can be earned on the scale, with higher scores indicating greater social isolate behaviours. However, the initial development of the SIASA involved 40 items but after construct validation, the number of the items was reduced to 24 . In order words 20 items of SIASA did not survive the construct validation. Out of the 20
Table 1: That there is a significant difference in the number of male and female secondary school adolescents who participated in the program. The same results apply to age, tribe and religion of the participants.

\begin{tabular}{|c|c|c|c|c|c|}
\hline $\begin{array}{c}\text { Demographic } \\
\text { characteristics }\end{array}$ & CRT Group & No Intervention & N (\%) & $\mathbf{X}^{0}$ & $\mathbf{P}$ \\
\hline Gender & & & & \\
\hline Female & 17 & 15 & $32(51.13)$ & & \\
\hline Age & & 14 & $30(45.84)$ & 4.41 & .002 \\
\hline E20 & $6 a$ & 4 & $10(15.63)$ & & \\
\hline $20-30$ & 26 & 25 & $51(79.69)$ & & \\
\hline$>30$ & 2 & 1 & $3(4.69)$ & 35.56 & .000 \\
\hline Tribe & 18 & 17 & $36(56.80)$ & & \\
\hline Igbo & 14 & 12 & $26(41.18)$ & 11.02 & .000 \\
\hline Others & & & & & \\
\hline Religion & 20 & 18 & $20(31.71)$ & & \\
\hline Christian & 8 & 9 & $18(28.58)$ & 8.02 & .000 \\
\hline Moslem & & & & \\
\hline
\end{tabular}

items, 16 items loaded more than 3.50 in more than one factor while the remaining 4 items could not load up to 0.35 in any of the factors. After that, the internal consistency reliability index of 0.72 was obtained using Cronbach Alpha method for the 24 
items of SIASA that survived the construct validation. Besides, the test-retest reliability of the SIASA was established to be 0.83 using pearson's product-moment correlation coefficient. This was done by re-administering the SIASA after the 2 weeks of first administration.

\section{Adjustment Scale of Social Isolates (ASSI)}

Adjustment Scale of Social Isolates (ASSI) developed by the researchers is a 10 item scale with five response options of Not At All (1), Almost Never (2), Sometimes (3), Nearly Always (4), and Always (5) with lowest and highest scores of 10 and 50 respectively. Example of item statement on ASSI is "I associate freely with Friends". However, the initial development of the ASSI involved 19 items but after construct validation, the number of the items was reduced to 10. In other words, 9 items of ASSI did not survive the construct validation. Out of the 9 items, 7 items loaded more than 3.50 in more than one factor while the remaining 2 items could not load up to 0.35 in any of the factors. After that, the internal consistency reliability index of 0.71 was obtained using Cronbach Alpha method for the 10 items of ASSI that survived the construct validation. Besides, the test-retest reliability of the ASSI was established to be 0.86 using pearson's product-moment correlation co-efficient. This was done by re-administering the ASS1 after the 2 weeks of first administration.

\section{Procedure}

A demographic questionnaire was administered to the eligible participants to access their age, gender, and location as secondary school adolescents. In order to remove randomization bias, information from the demographic questionnaire were not made know to the person who randomized the participants to experimental and control conditions. Before the commencement of the testing and treatment package, the researchers assured the participants of confidentiality of interactions and personal information as they work together in self disclosure. Thereafter, pre-treatment assessment (pre-test) was conducted using the SIASA and ASSI in order to collect baseline data (Time 1). After that, the experimental group was exposed to 90 minutes of the CRT program twice a week for period of 6 weeks. The treatment took place between September and November, 2019. Post-test (Time 2) assessment was conducted 1 week after the last treatment session. Besides, a follow-up assessment was conducted after 2 months of the treatment (Time 3). Data collected from the experimental group at each evaluation were compares to that from the nonintervention control group.

\section{Intervention program}

The program that was used in this study was designed by Ncheke [2] to improve the experimental group's ability to analyze their social isolation and was based on Beck's Cognitive Restructuring Technique (CRT). Beck [26] outlined ten fundamental principles of cognitive therapy, and these principles guided the development of eight, 90 minutes group education sessions, a general plan for the whole process was prepared as well as specific plans for each session. The experimental program content focused on automatic thoughts related to social isolation behavior. During each of the treatment sessions, 30 minutes were spent on the automatic thoughts, while the remaining 60 minutes were spent on the intermediate thoughts or unrealistic thoughts and discussion sessions. In addition, based on the cognitive, affective and behavioural dimensions of social isolation, problem-solving, cognitive and behavioural techniques were used together. The contents of the session were supported by purposive activities, visual material (illustrations, diagrams, among others).

Each session began with a summary of the previous session (except for the first session), followed by discussing the homework, explaining the current session's agenda, and warm-up activities. The session ended with summarizing, giving feedback and homework (except for the eight session), and a closing activity. The general outlines of the session and brief information are provided below;

- To help adolescents become familiar with the basic logic of the CRT-based psycho educational program and determine their personal goals.

- To ensure that adolescents were informed about the cognitive restructuring technique.

- To ensure that adolescents reframe from negative and unrealistic thoughts to realistic and positive thinking.

- To assist adolescents in adjusting their social isolate behaviours.

- To assist adolescents that whenever unpleasant and unfortunate activating events occur in people's lives, they have a choice of making themselves feel healthily and self-helping sorry among others.

- To help adolescents learn that man's unrealistic thought leads to his undesirable behavior.

- To help adolescents learn that man's propensity to think negatively can be checked and reversed to ensure wellordered, positive, logical and rational life as a result of cognitive restructuring.

The manual as adopted from Ncheke [2] was written in English and can be accessed from https://www.researchgate. net (publication) edu.ng). Effects of cognitive restructuring and rational emotive behavioural therapy on social isolate behaviours of secondary school student.

\section{Data analysis}

The efficacy of cognitive restructuring technique on adjustment of social isolates in a sample of Nigeria secondary school adolescents in Enugu state, Nigeria was established statistically using repeated measures analysis of variance (ANOVA). Partial Eta squared and adjusted $\mathrm{R}^{2}$ values were used on the dependent measure. The assumption of the sphericity of the test statistics was tested using the Mauchly test of sphericity which was not significant (Mauchly W=0.768, $\mathrm{P}=.647$ ), implying that the assumption was not violated. Thus, 
the variances of the differences between all combinations of the related measures are equal. The analysis was done using statistical package for social sciences version 18.0.

\section{Schematic representation of the method and materials 3}

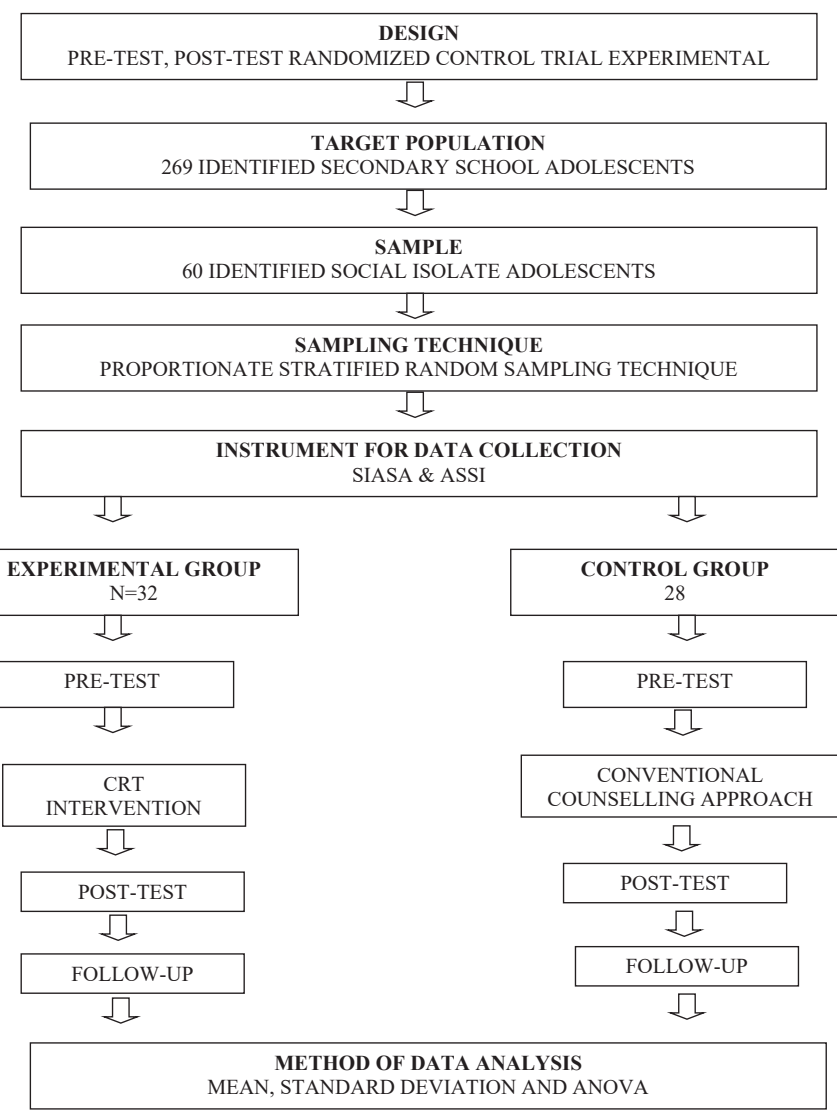

\section{Results}

Table 2 revealed that there was no significant difference between the experimental and control groups in initial social isolates of secondary school adolescents by SIASA $F(1,59)=$ $0.131, \mathrm{P}=.811, \mathrm{n}^{2}=0.005, \Delta \mathrm{R}^{2}=0.006$. At the post-treatment and follow-up measures, the efficiencies of CRT on the adjustment of social isolate adolescents were significant, $\mathrm{F}(1,59)=612.421$, $\mathrm{P}=0.00, \mathrm{n}^{2}=.701, \Delta \mathrm{R}^{2}=.716$.

Similarly, using ASSI as a measure, there was no significant difference in the initial social isolation of the participants, $\mathrm{F}(1,59)=0.423, \mathrm{P}=.621, \mathrm{n}^{2}=.007, \Delta \mathrm{R}^{2}=.010$. At the posttreatment and follow-up measures, the efficienties of CRT on the adjustment of social isolate adolescents were significant, $\mathrm{F}(1,59)=107.432, \mathrm{P}=.000, \mathrm{n}^{2}=.589, \Delta \mathrm{R}^{2}=.651$, and $\mathrm{F}(1,59)=$ 121.231, $\mathrm{P}=.000, \mathrm{n}^{2}=701, \Delta \mathrm{R}^{2}=716$.

Table 3 revealed that the mean adjustment scales of social isolate of the intervention group were significantly difference of pre-treatment, post-treatment and follow-up measures, $\mathrm{F}(2-31) 45.623, \mathrm{P}<0.05, \mathrm{n}^{2}=.680$.

Table 4 gives us the significance level for difference between the individual time points. It shows that there were significant differences in social isolate behaviors of Secondary School adolescents between post-treatment and pre-treatment $(\mathrm{P}=0.000)$, and between pre-treatment and and follow-up $(\mathrm{P}=$ 0.000). This implies that the social isolate behaviours of the adolescents drastically adjusted after the intervention program.

\section{Discussion of the results}

The findings of the study revealed that at the posttreatment and follow-up measures, the efficacy of cognitive restructuring on the adjustment of social isolate adolescents was significant. This finding has shown the superiority nature of the CRT over the conventional counseling approach in the adjustment of social isolate behaviors among secondary school adolescents. The adolescents who were counseled on the dangers of social isolate using CRT were optimally motivated during the intervention sessions and that led to the drastic adjustment in their social isolation after the intervention and even at the follow-up measures. This finding is similar to the finding of Undaah (2015) whose empirical finding indicated that isolates are taught to refrain from negative thoughts and develop a mindset that enables them to persist better in doing aversive tasks using CRT. Supporting these findings are the findings of Livingstone, Mejo, Umah, Enajedu, Ncheke and Umah $[4,22,23,25]$. Inappropriate behavior can be adjusted or rather reduced through behavior modification techniques. Different kinds of behavior modification techniques such as rational emotive behavioural therapy, psychodrama, role therapy, avertive therapy, reinforcement among others have been used for intervention on maladaptive behavior among school children [4], Nickarson [17], Okeke [18], and Anagboju (2005). According to Adumh [20,27] psychological principles and the experiences of mental health counselor and those therapists who have worked with isolated persons support the following techniques for helping rejected and isolated students achieve a place in the class group. However, all these techniques are used in counseling approach like Cognitive Restructure Technique (CRT).

The above findings validated the efficacy of the CRT intervention for adjusting social isolate adolescents in public schools in Enugu state, Nigeria. The implication of these findings is that if secondary school adolescents are not properly counseled thus social isolation behaviour will continue to increase.

\section{Contributions of the study}

This study explored an area which addressed the contemporary problems among adolescents in Nigeria secondary schools. The intervention is considered timely, given the potential effects of social isolation on adolescents adjustment in secondary schools. The intervention successfully validated the effectiveness of CRT in adjusting social isolation among adolescents using a randomized control trial. The use of experimental and control groups enabled the researchers to compare both within-group factors and between-group factors. 
Table 2: Repeated Analysis of variance for the efficacy of cognitive restructuring technique on adjustment of social isolates adolescents.

\begin{tabular}{|c|c|c|c|c|c|c|c|c|c|}
\hline Time & Measures & Group & Mean(SD) & $\mathbf{F}$ & $\mathbf{P}$ & $\mathbf{N}^{2}$ & $\Delta \mathbf{R}^{2}$ & $95 \%$ & C1 \\
\hline \multirow[t]{2}{*}{ Pre- Treatment } & SIASA & Experi mental control & $\begin{array}{c}82.21(5.44) \\
85.13(4.02\end{array}$ & .131 & .811 & .005 & .006 & 0.01 & 172 \\
\hline & ASSI & $\begin{array}{l}\text { Experi mental } \\
\text { Control }\end{array}$ & $\begin{array}{l}41.44(10.3) \\
40.82(2.33)\end{array}$ & .423 & .621 & .007 & .010 & 0.26 & 1.99 \\
\hline \multirow[t]{2}{*}{ Post Treatment } & SIASA & $\begin{array}{l}\text { Experi mental } \\
\text { Control }\end{array}$ & $\begin{array}{l}21.42(2.33) \\
73.33(8.11)\end{array}$ & 787. 123 & .000 & .742 & .771 & 703.23 & 801.5 \\
\hline & ASSI & $\begin{array}{l}\text { Experi mental } \\
\text { Control }\end{array}$ & $\begin{array}{l}15.87(2.43) \\
41.60(5.42)\end{array}$ & 107. 432 & .000 & .589 & .651 & 100.35 & 120.67 \\
\hline \multirow[t]{2}{*}{ Follow-up } & SIASA & $\begin{array}{l}\text { Experi mental } \\
\text { Control }\end{array}$ & $\begin{array}{l}20.11(2.01) \\
71.10(7.21)\end{array}$ & 612.421 & .000 & .701 & .716 & .32 & 685.22 \\
\hline & ASSI & $\begin{array}{c}\text { Experi } \\
\text { mental } \\
\text { Control }\end{array}$ & $\begin{array}{l}14.05(1.47) \\
40.89(5.02)\end{array}$ & 121. 231 & .000 & 698 & .706 & 108.56 & 136.74 \\
\hline
\end{tabular}

SIASA: Social Isolate Assessment Scale for Adolescents; ASSI: Adjustment Scale of Social Isolates; Mean= (SD)

Mean= (Standard Deviation); $\mathrm{P}=$ Probability value; $\mathrm{Cl}=$ Confidence Interval; $\mathrm{N}^{2}=$ Effect size; $\mathrm{DR}^{2}=$ Adjusted $\mathrm{R}^{2}$

Table 3: Test of with in Subjects effects for thec Intervention group.

\begin{tabular}{|c|c|c|c|c|c|c|}
\hline Source & $\begin{array}{c}\text { Type } \\
\text { III sum } \\
\text { squares }\end{array}$ & of Df & $\begin{array}{c}\text { Mean } \\
\text { Square }\end{array}$ & $\mathbf{F}$ & $\begin{array}{c}\text { Sign. } \\
\text { square }\end{array}$ & $\begin{array}{c}\text { Partial Eta } \\
\text { square }\end{array}$ \\
\hline $\begin{array}{c}\text { Measure: ASS } \\
\text { Time }\end{array}$ & & & & & \\
\hline $\begin{array}{c}\text { Sphericity } \\
\text { Assured }\end{array}$ & 93.335 & 2 & 45.623 & 11.542 & .000 & .680 \\
\hline $\begin{array}{c}\text { Greenhouse- } \\
\text { Geisser }\end{array}$ & 93.335 & 1.862 & 44.523 & 11.542 & .000 & .680 \\
\hline $\begin{array}{c}\text { Huguh-felt } \\
\text { Lower-bound }\end{array}$ & 93.335 & 2.000 & 43.624 & 11.542 & .000 & .680 \\
\hline
\end{tabular}

Table 4: Post hoctest for the Significant effect of time.

\begin{tabular}{|c|c|c|c|c|}
\hline (I) Time & $(\boldsymbol{J})$ Time & Mean difference (1-9) & Std. Erro & Sig. \\
\hline \multirow{2}{*}{ Pre-treatment } & Post-treatment & 61.550 & .008 & .000 \\
& Follow-up & 61.122 & .007 & .000 \\
\hline \multirow{2}{*}{ Post-treatment } & Pre-treatment & -61.551 & .008 & .000 \\
& Follow-up & -534 & .008 & .000 \\
\hline \multirow{2}{*}{ Follow-up } & Post-treatment & -61.122 & .007 & .000 \\
& Follow-up & .532 & .008 & .000 \\
\hline
\end{tabular}

\section{Limitations}

Like other empirical-based studies, this present study has some limiting factors. The study utilized data from the criterion-referenced point of view to evaluate the effectiveness of CRT on the adjustment of social isolation among adolescents, without considering the moderating effects of demographic variables like gender, age and some personality characteristics.

The cognitive configuration used by the experiment were effective for helping the experimental group to begin adjusting tasks even when they did not feel like working. In addition, the experimental group in this study reported dislike doing assignments in a group, read in group with classmates and not happy going to school as causes of the social isolation behavours. These may have affected the outcome of the study. Consequently, the generalization of the findings should be done with care. However, future studies should explore how these demographic variables could moderate the efficacy of CRT on the adjustment of social isolate adolescent.

\section{Conclusion and Recommendation}

Based on the findings of the study, the researchers concluded that CRT is efficacious in the adjustment of social isolation among adolescents in public secondary schools. Based on the conclusion, it is therefore profitable, that guidance counselors in secondary schools should be properly trained on how to use CRT in adjusting social isolation among adolescents. It is also important that education authorities or rather federal government should provide enough guidance counselors in the various secondary schools who will assist in the counseling of the adolescents on the dangers of social isolation using CRT.

\section{Compliance with ethical standards}

The authors adhered to the ethical standard specification of the American Psychological Association, APA (2017), and with that of the world Medical Association (2013).

\section{References}

1. World Health Organization (2014) Adolescence. Link: www.britannica.com.

2. Ncheke DC (2011) Effects of individual and group counseling on the adjustment of social isolates. Unpublished Ph.D thesis, Nsukka. University of Nigeria, Nsukka.

3. Igbo EN (2003) Basic sociology. Enugu, CIDJAF Publishing Press.

4. Enajedu EE, Ncheke DC, Umah SS (2020) Efficacy of Rational emotive beahvioural therapy counseling on adjustment of social isolates. International Journal of Arts and Social Science Research 3. Link: http://bit.ly/3uvWDV0

5. Adams EH (2007) The psychological dimensions of Arthrin's.

6. Nwoye A (2007) Counselling psychology for Africa. Enugu: Fabs Arieh, (Nig).

7. Ade CC (2017) Cognitive Restructuring and Adolescents. Journal of Education 6: $101-122$

8. Obiweluozo EP, Ibiam JU (2008) Adjustment strategies of retired primary school teachers in Enugu State. Journal of Educational Foundations 5: 132146.

9. Okojie AC, Egbo CC, Adah LA (2017) Adolescents and Maladaptive behavior.

10. Njo CN (2017) Isolates in the senior secondary school. Stoke-on-kent. Truthan Books. 
11. Leo TA (2018) Counselling effective and students learning.

12. Gronlund NE, Anderson L (2000) Personality characteristics of socially neglected and socially rejected junior high school pupils. Educational Administration and Supervision 42: 335-342.

13. Goertzen SM (2006) Factors relating to opinion of seventh-grade children regarding the acceptability of certain behaviours in the peer groups. J Genet Psychol 94: 29-34. Link: http://bit.ly/3dNGh49

14. Calif CN (2017) Practical approach to isolation behavior. London: David Fulton.

15. Lunni CS (2018) Condition of attention as a source of adjusting isolate beahviour.

16. Mobok KA (2019) Psychology science and understanding.

17. Nickarson RF (2002) Child development. An introduction Houghton, Nifflin Company, Boston.

18. Okeke BA (2002) Techniques and practicum in guidance and counselling. Enugu. Snaap Press (Nig.).

19. Anagbogu MA (2005) Foundations of guidance and counseling for colleges and Universities. $2^{\text {nd }}$ Ed. Enugu. Academic Publishing Company.
20. Adumh AC (2019) Fundamental of Guidance. Boston: Hoghton willflin. W.

21. Beck JS (2011) Cognitive behavior therapy: Basics and beyond. Second Edition. New York, London: The Guilford Press. Link: https://bit.ly/3qW10qk

22. Umah SS (2015) Effects of cognitive restructuring and bibbliotherapy techniques on anger manifestation of secondary school students. Unpublished Ph.D. Thesis, Nsukka, University of Nigeria, Nsukka.

23. Mejo NO (2016) Effect of cognitive restructuring in tendencies to engage in examination malpractices of students. Journal of Education 6: 112-123.

24. Enofa DC (2017) Cognitive restructuring technique and unadaptive behavior Journal of Education 6: 10-27.

25. Livingstone CN (2008) Cognitive behavioural approach. New York, NY: McGraw Hill.

26. Beck CT (2001) Predictors of postpartum depression: An update. Nurs Res 50 : 275-285. Link: http://bit.ly/2NJzNbZ

27. Feinberget M (2007) An analysis of expressions used by adolescents of varying economic levels to describe accepted and rejected peers. Journal of Genetic psychology 91: 29-34.
Discover a bigger Impact and Visibility of your article publication with Peertechz Publications

Copyright: @ 2021 Ncheke DC, et al. This is an open-access article distributed under the terms of the Creative Commons Attribution License, which permits unrestricted use, distribution, and reproduction in any medium, provided the original author and source are credited.

Citation: Ncheke DC, Nwosu N, Egenti NT, Enajedu EE, Ede MO, et al. (2021) Efficacy of cognitive restructuring technique on adjustment of social isolates in a sample of nigerian secondary school adolescences. Glob J Medical Clin Case Rep 8(1): 016-023. DOI: https://dx.doi.org/10.17352/2455-5282.000119 